\title{
NARRATIVAS (AUTO) BIOGRÁFICAS, MEMÓRIA E DOCÊNCIA
}

\author{
Narrative (auto) biográficas, memory and teaching
}

Sebastião Silva Soares ${ }^{1}$

\begin{abstract}
RESUMO: Este artigo tem por objetivo desenvolver uma reflexão sobre as narrativas (auto) biográficas no âmbito da formação e do desenvolvimento profissional de professores, além da sua aplicação na pesquisa em educação. Para subsidiar a análise, apoiamo-nos em Souza (2008), Passeggi (2010), Josso (2010), Clandinin; Connelly (2015), Oliveira (2011), Morinã (2017), Ferrarotti (2010), Bolívar; Domingo; Fernández (2001), Larrosa (2002), Nóvoa; Finger (2010), Zabalza (2004), dentre outros. Os dados salientam que narrativas potencializam a história de vida de professores, como campo de saber e conhecimento. Logo, a experiência narrada é compreendida pelos interlocutores como um texto vivo, simbólico e autoformativo.
\end{abstract}

Palavras-chave: Narrativas (auto) biográficas. História de vida. Formação de professores. Desenvolvimento profissional.

ABSTRACT: This article aims to develop a reflection on the (auto) biographical narratives in the scope of teacher training and professional development, as well as its application in education research. To support the analysis, we rely on Souza (2008), Passeggi (2010), Josso (2010), Clandinin; Connelly (2015), Oliveira (2011), Morinã (2017), Ferrarotti (2010), Bolivar; Sunday; Fernández (2001), Larrosa (2002), Nóvoa; Finger (2010), Zabalza (2004), among others. The data highlight that narratives enhance the life history of teachers as a field of knowledge and knowledge. Therefore, the narrated experience is understood by the interlocutors as a living, symbolic and self-formative text.

Keywords: Biographical (self) narratives. Life's history. Teacher training. Professional development.

\section{INTRODUÇÃO}

O método biográfico permite que seja concedida uma atenção muito particular e um grande respeito pelos processos das pessoas que se formam (...) constitui uma abordagem que possibilita ir mais longe na investigação e na compreensão dos processos de formação e dos subprocessos que o compõe.

\footnotetext{
1 Professor na Universidade Federal do Tocantins (UFT). Mestre pela Universidade de Brasília (UnB). Doutorando em Educação pela Universidade Federal de Uberlândia (UFU). E-mail: sebastiaosilva@uft.edu.br
} 
(FINGER; NÓVOA, 2010, p. 23)

Com base nessa epígrafe, buscamos neste artigo tecer uma reflexão acerca das narrativas (auto) biográficas na formação e no desenvolvimento profissional de professores, partindo do pressuposto que essa abordagem de formaçãoinvestigação, possibilita aos docentes um conhecimento de si e do Outro, mas também, uma reflexão e ressignificação acerca da própria identidade pessoal e profissional (BOLÍVAR; DOMINGO; FERNÁNDEZ, 2001). Do mesmo modo, esse método emerge como instrumento de investigação nas ciências da educação (CLANDININ; CONNELLY, 2015).

Para subsidiar nossa escrita do artigo, realizamos uma pesquisa bibliográfica, a partir dos estudos de Souza (2008), Passeggi (2010), Josso (2010), Clandinin; Connelly (2015), Oliveira (2011), Morinã (2017), Ferrarotti (2010), Nóvoa; Finger (2010), Bolívar; Domingo; Fernández (2001), Larrosa (2002), Guimarães (1997), Bossi (1994), Zabalza (2004), dentre outros autores que dialogam sobre o tema em questão.

Este trabalho foi organizado em três seções: inicialmente, apresentamos uma reflexão sobre o método (auto) biográfico nas ciências da educação. No tópico seguinte, tecemos uma análise das narrativas (auto) biográficas nos estudos sobre a história de vida de professores. Por fim, desenvolvemos uma reflexão no que diz respeito às narrativas, especificamente, os gêneros discursivo-textuais ${ }^{2}$ : o memorial formativo e o diário biográfico, como dispositivos de formação e investigação no campo da docência.

\section{O ESTUDO (AUTO) BIOGRÁFICO}

O método (auto) biográfico ganhou evidência no cenário educacional após a década de 1980, quando as pesquisas realizadas no período começaram a valorizar elementos intersubjetivos e subjetivos, que envolvem a formação e a prática pedagógica dos professores, como personagens ativos do processo, e não apenas

\footnotetext{
${ }^{2}$ Neste trabalho, usaremos as denominações gêneros discursivo-textuais ou textuais, a partir dos trabalhos de Bakhtin (2003), nos quais a linguagem é constituída de enunciados que refletem as particularidades e finalidades de cada campo da atividade humana.
}

Cadernos Cajuína, V. 4, N. 1, 2019, p. 08 - 21.

ISSN: 2448-0916 
espectadores das ações desenvolvidas nas escolas (NÓVOA; FINGER, 2010). Para os autores,

[...] por um lado ela permite identificar as características seguidas pelos formadores (uma categoria profissional que ainda não está institucionalizada) na sua própria dinâmica de formação e na aquisição de competências técnicas específicas à função que desempenham; por outro lado, ela facilita a definição dos saberes e das formações mais necessárias para o exercício da função de formador. (NÓVOA; FINGER, 2010, p. 26)

Esses teóricos argumentam que, há na pesquisa (auto) biográfica ou método biográfico, assim denominados, a valorização de aspectos relacionados aos processos de vida e à formação dos sujeitos, que foram negligenciados ou omitidos no campo das ciências tradicionais. Assim, os trabalhos biográficos ou autobiográficos, com foco na história de vida de professor, não surgem apenas com a finalidade de aprimorar os elementos metodológicos dos estudos, mas, sobretudo, promover a compreensão do método, como dispositivo de formação, autoformação e investigação. Por essas abordagens (auto) biográficas, é possível observar a valorização da vida da pessoa em sua integralidade e singularidade. Por outro lado, torna-se exequível o desvelamento de particularidades e pluralidades da história de vida dos mestres docentes. Dito de outro modo, faz-se necessário estabelecer leituras cruzadas que envolvem o "eu" e o "Outro" como parte do processo da identidade em (re) construção.

Ferrarotti (2010), no texto "Sobre a autonomia do método biográfico", afirma que o método biográfico surgiu diante da necessidade de uma revisão metodológica da sociologia clássica, além do interesse das pessoas buscarem compreender os itinerários formativos, consequentemente, "subjetivo, qualitativo, alheio a todo o esquema hipótese-verificação, o método biográfico projeta-se à partida fora do quadro epistemológico estabelecido das ciências sociais" (FERRAROTTI, 2010, p. 37).

Para o autor referenciado, a especificidade do método (auto) biográfico está no fato de sua proposta metodológica reivindicar o reconhecimento das relações intersubjetivas que permeiam a compreensão do universal pelo singular, superando a máxima do filósofo Aristóteles: "Só há ciências do geral" (FERRAROTTI, 2010, p. 48). Dito de outra forma, para além da generalização de dados propagados pelas 
ciências tradicionais, na perspectiva (auto) biográfica fica evidenciada a interpretação e compreensão da história de vida do sujeito, como atividade e interação de uma práxis humana.

Passeggi (2010) afirma que os estudos (auto) biográficos integram os elementos do pensamento, da linguagem e da práxis social, como meio de interpretação das representações e sentidos que os sujeitos atribuem aos itinerários de vida e da formação. Ou seja, a linguagem desempenha o papel de interação entre os sujeitos, logo, a palavra é instrumento de expressão social e compreensão de si.

Assim, uma abordagem (auto) biográfica não visa neutralizar as dimensões sociais da sua reflexão, pois "as pesquisas são guiadas pelo desejo de considerar o que a pessoa pensa sobre ela e sobre o mundo, como ela dá sentido às suas ações e toma consciência de sua historicidade" (PASSEGGI, 2010, p. 122). No processo (auto)biográfico, seja modalidade oral seja escrito, o sujeito e pesquisador se apropria da narrativa de vida como objeto de reflexão e formação (GUIMARÃES, 1997).

Nessa perspectiva, Morinã (2017) argumenta que as pesquisas biográficonarrativo possibilitam estabelecer o desenvolvimento humano na pesquisa em educação. Além disso, têm o potencial de promover mudanças nas estruturas de poder e nas formas de compreensão de produção do conhecimento. Para a autora, essa abordagem de estudo e formação, amplia os processos democráticos entre pesquisador e pesquisados, de modo a superar a dimensão hierárquica sujeitoobjeto presente nas investigações. Ficam perceptíveis, nesse âmbito narrativo, na sua visão, processos de emancipação humana, pois são desveladas vozes que, na maioria das vezes, foram silenciadas na produção do conhecimento em âmbito universal.

No que diz respeito aos aspectos metodológicos nas abordagens (auto) biográficas, Souza (2008) e Passeggi (2010) concordam, ao afirmarem que é evidente a multiplicidade de trabalhos (teses, dissertações e artigos), que têm surgido no país com o uso (auto) biográfico, mais especificamente na realidade educacional, após a criação dos Congressos Internacionais de Pesquisa sobre a Pesquisa (Auto) Biográfica (CIPA) e a Associação Brasileira de Pesquisa (Auto) Biográfica (BlOgraph). 
Ao analisar parte da literatura produzida da área no portal de periódicos do Centro de Aperfeiçoamento de Pessoal de Nível Superior (CAPES), Ramos; Oliveira; Santos (2017), observaram que a maioria desses estudos tem inspiração nos trabalhos europeus na área da formação de adultos. Os autores ressaltam ainda que as pesquisas apresentam multiplicidade de opções teóricas, estratégias metodológicas e ampliação de aplicação em diversas áreas de conhecimento. Nesse aspecto, diversos instrumentos têm sido empregados nas investigações (auto) biográficas, como fontes de formação e produção de dados, tais como: memoriais, relatórios de estágio, cartas, diários, fotografias, caderno de memórias, ateliês biográficos, e as entrevistas narrativas (BOLÍVAR; DOMINGO; FERNÁNDEZ, 2001).

Pela produção desses recursos, como campo discursivo, é possível captar as cadeias de sentidos e significados que elucidam e entrecruzam a história de vida dos sujeitos por meio das suas narrativas. Em linhas gerais, acreditamos que as (auto) biografias, elaboradas a partir de variados gêneros textuais, configuradas como instrumentos autoformativos, têm o potencial de criar espaços discursivos, nos quais os docentes podem construir uma reflexão e interpretação sobre a sua identidade, além de um processo de ressignificação da própria prática pedagógica, pois, esses textos, por meio de um mediador ou formador, podem se tornar instâncias compreensivas sobre o conhecimento de si e do Outro.

\section{A NARRATIVA NOS ESTUDOS (AUTO) BIOGRÁFICOS}

A narrativa (auto) biográfica se baseia nas relações construídas pelos sujeitos em torno da compreensão de si e dos processos de reflexão e ressignificação da identidade pessoal e profissional. Nessa direção, a produção da pesquisa narrativa é compreendida como um meio de compreender experiências dos indivíduos de forma narrativa (CLANDININ; CONNELLY, 2015). Para os autores, a pesquisa narrativa corresponde aos processos de significação e representações que os sujeitos atribuem as experiências vividas ou presenciadas num dado contexto e situação, por meio do exercício do contar, recontar e reviver.

Pelo estudo narrativo, a experiência, entendida aqui como marca que atravessa a constituição identitária das pessoas (LARROSA, 2002), ganha sentidos e significados, que permitem os sujeitos construírem uma análise maior sobre si próprio e seu próximo. Para Larrosa (2012), por meio do exercício da reflexão, é 
possível compreender as experiências, como elemento que nos tocam, nos acontece para além da mera informação das vivências cotidianas:

Por isso, o saber da experiência é um saber particular, subjetivo, relativo, contingente, pessoal. Se a experiência não é o que acontece, mas o que nos acontece, duas pessoas, ainda que enfrentem 0 mesmo acontecimento, não fazem a mesma experiência. $O$ acontecimento é comum, mas a experiência é para cada qual sua, singular e de alguma maneira impossível de ser repetida. O saber da experiência é um saber que não pode separar-se do indivíduo concreto em quem encarna. Não está, como o conhecimento científico, fora de nós, mas somente tem sentido no modo como configura uma personalidade, um caráter, uma sensibilidade ou, em definitivo, uma forma humana singular de estar no mundo, que é por sua vez uma ética (um modo de conduzir-se) e uma estética (um estilo) (LARROSA, 2002, p. 27). (Grifo Nosso)

O autor acima disserta que o fenômeno experienciado por determinado ser é pessoal e social, pois embora tenham compartilhado determinada situação juntos, é perceptível evidenciar em seus relatos, elementos que correspondem à maneira que cada um atribui significados para a experiência vivida, de modo singular e particular. Assim, as (auto) biografias tornam-se alternativas de formação e pesquisa, que permitem interpretar e compreender experiências que atravessam a constituição dos sujeitos, como seres narrativos e contadores de estórias.

Isso porque, o exercício do pensar é narrativo e situado, logo, por meio da memória os indivíduos buscam descrever, refletir e interpretar as experiências vividas, como autores e personagens das suas histórias de vida. O enfoque narrativo permite a elaboração de um novo texto acerca das experiências vividas e compartilhadas, pois as narrativas não correspondem ao fato real presenciado, mas revivido, interpretado e ressignificado "nos espaços-tempos em que se relevam" pelos sujeitos (FONTOURA, 2010, p. 92).

As narrativas (auto) biográficas possibilitam os indivíduos desenvolver interpretação e compreensão das singularidades e da pluralidade da vida humana, como uma teia tecida de significado e representações, evocados entre o exercício da memória e a construção de identidades situadas e inscritas no tempo e espaço, pois "lembrar não é reviver, mas refazer, reconstruir, repensar, com imagens e ideias de hoje, as experiências do passado" (BOSI, 1994, p. 55). O aspecto narrativo (auto) biográfico, no caso da docência, potencializa os processos de reflexão do professor, de modo individual e coletivo, superando as diversidades do reconhecimento de si e 
valorização do outro, como parte integrante da própria identidade, concebida numa dimensão "histórica, contingente e relacional" (SILVA, 2015, p. 104).

Dessa forma, as narrativas desafiam os professores a tomarem consciência dos processos formativos e profissionais que constituem e marcam a sua identidade pessoal e profissional, pois elas têm o potencial de "explicitar a singularidade e, com ela vislumbrar o universal, perceber o caráter processual da formação e da vida, articulando espaços, tempos e as diferentes dimensões de nós mesmos, em busca de uma sabedoria de vida" (JOSSO, 2004, p. 9). Nesse sentido, a narrativa conduz o sujeito a desenvolver uma reflexão sobre o sentido da vida, os significados das experiências vivenciadas em âmbito individual e coletivo.

Por meio das narrativas é possível o professor redescobrir marcas, experiências e vivências do passado que, no tempo presente, assumem novas dimensões e interpretações sobre a sua própria existência. As narrativas de formação também se tornam ferramentas significativas que possibilitam rever crenças e representações sobre o fazer pedagógico, como aprendizagem de vida e formação pessoal e profissional. No caso do pesquisador, a pesquisa narrativa oferece ferramentas essenciais para a interpretação e compreensão de sentidos, que os sujeitos atribuem ao fenômeno observado como um texto novo, composto de cenários, enredos, tramas e identidades, de modo singular e coletivo que tecem a história de vida pessoal e profissional de cada professor.

\section{A NARRATIVA (AUTO) BIOGRÁFICA E A FORMAÇÃO DE PROFESSORES}

Diferentes autores, como Souza (2008), Passeggi (2010), Josso (2010), Oliveira (2011), Morinã (2017), Nóvoa; Finger (2010), Bolívar; Domingo; Fernández (2001), Zabalza (2004) dentre outros, têm salientado que a narrativa (auto) biográfica, oral e escrita, com os professores, tem possibilitado que eles desenvolvam um pensar sobre o conhecimento de si, a revisão da atividade docente e melhorias da prática pedagógica, particularmente, pelo caráter heurístico, subjetivo e intersubjetivo que permeiam suas narrativas.

Frente a esses estudos, focaremos a nossa reflexão, em torno da narrativa de si, especificamente, nos gêneros textuais: o memorial de formação e o diário biográfico-reflexivo, pois entendemos que narrativas (auto) biográficas escritas, em 
particular, desvelam sentidos, significados e interação, aspectos essenciais na formação e desenvolvimento do professor. Isso porque:

\begin{abstract}
A atividade docente não é exercida sobre um objeto, sobre um fenômeno a ser conhecido ou uma obra a ser produzida. Ela é realizada concretamente numa rede de interações com outras pessoas, num contexto onde o elemento humano é determinante e dominante e onde estão presentes símbolos, valores, sentimentos e atitudes, que são passiveis de interpretação e decisão. (TARDIF, 2014, p. 49-50)
\end{abstract}

Desse modo, a produção da narrativa escrita permite que os professores deem sentidos às experiências e vivências construídas ao longo da vida, ou seja, eles têm a possibilidade de indagar diversos processos de socializações que marcam sua identidade pessoal e profissional como professor. Em outro aspecto, entendemos que a produção escrita (auto) biográfica "possibilita ao sujeito assumir o papel de protagonista ao criar/produzir textos ao invés de apenas consumi-los" (OLIVEIRA, 2011, p. 290). Para a autora, pensar a produção narrativa no âmbito da docência é construir processos que venham subsidiar a formação do professor e seu desenvolvimento profissional, como autor e protagonista da sua história de vida.

Nesse caso, as narrativas escritas pelos docentes podem revelar representações e significações, que eles produzem sobre si próprios, suas crenças, estilos do ser e estar docente, dos alunos, das instituições escolares, as condições de trabalho e prática pedagógica (BOLÍVAR; DOMINGO; FERNÁNDEZ, 2001). Em outras palavras, a prática da narrativa escrita (auto) biográfica proporciona o professor embarcar numa "viagem" entre os fatos passados e presente, num percurso cheio de incertezas e desconforto; mas divertido, formativo e desafiador (HOLLY, 1992). Isso vem reforçar, portanto, a narrativa (auto) biográfica como prática reflexiva, formativa e investigativa. Por outro lado,

[...] Constitui-se numa aprendizagem experiencial, ao colocar o sujeito numa prática subjetiva e intersubjetiva do processo de formação, tecida nas experiências e aprendizagens ao longo da vida e expressa no texto narrativo, porque congrega e carrega experiências diferentes e diversas, a partir das próprias escolhas, das dinâmicas e singularidades de cada vida. (OLIVEIRA, 2011, p. 293) 
Dessa forma, a narrativa escrita, como processo subjetivo e intersubjetivo, demonstra ao professor e produtor do próprio texto da vida, marcas e elementos que antes não foram refletidos ou interpretados como parte integrante da constituição da sua identidade. Ao produzir a narrativa de si, o docente experiencia múltiplas leituras e evocações esquecidas no imaginário, carregadas de sentimentos, alegrias, amor, medos, tristezas e superações. Por outro lado, as narrativas na pesquisa em educação nos possibilitam uma análise da singularidade da vida de cada mestre. Ou seja, por meio da prática narrativa (auto) biográfica escrita desenvolvemos um autoconhecimento sobre a existência do eu e do Outro, como dispositivo de formação, reinvenção e investigação.

\subsection{Memorial de formação}

A produção do memorial na educação é compreendida como uma prática discursiva importante na compreensão e apreensão dos processos formativos dos docentes. Nesse caso, o memorial é um dispositivo textual significativo na promoção de saberes e conhecimentos mobilizados pelos professores ao longo das trajetórias formativas, bem como uma ferramenta de avaliação desse itinerário pelas instituições de ensino.

Nesse âmbito, Câmara; Passeggi (2013) realizaram uma pesquisa acerca da tradição acadêmica do uso do memorial ${ }^{3}$ no contexto das universidades no país, caracterizado como instrumento de avaliação e/ou formação. O gênero memorial de formação, especificamente, para as autoras possui características significativas, tais como: o tipo da escrita, os autores, situação da escrita, objeto da escrita, principalmente, a construção de uma reflexão referente à formação, o desenvolvimento profissional e experiencial, sendo sua ênfase no curso em andamento.

O memorial é compreendido como uma escrita reflexiva e crítica, em torno da trajetória formativa construída pelos professores em formação inicial ou permanente. O memorial de formação, nesse aspecto, como ressaltado aqui, é um texto, em que o professor pode registrar as experiências e vivências entre acertos e

3 Em seus estudos, as autoras analisaram também o memorial acadêmico, como especificidade do gênero memorial no âmbito da universidade brasileira.

Cadernos Cajuína, V. 4, N. 1, 2019, p. 08 - 21.

ISSN: 2448-0916 
dificuldades nos vários momentos da sua formação de vida, escolar e acadêmica (CÂMARA; PASSEGGI, 2013).

Por meio desse recurso, é possível desvelar os processos intersubjetivos que permeiam os sentidos e significados atribuídos pelos professores no itinerário formativo. Consequentemente, a produção do memorial determina que o professor construa um pensar reflexivo no que diz respeito às aprendizagens, saberes e conhecimentos no percurso, de maneira crítica, criativa e autoral.

Todavia, a produção do memorial exige do formador e professor em formação o compromisso com o planejamento, elaboração e direcionamento das reflexões apresentadas no decorrer da narrativa. Uma das dificuldades vivenciada pelos docentes na construção do memorial é o trabalho reflexivo, pois as vivências relatadas em forma de palavras descrevem muito mais que informações sobre a trajetória formativa do professor, são evidenciados elementos da sua existência (SOARES; FONSECA, 2018).

É pertinente salientar, pois, que o trabalho de supervisão e tutoria do formador é relevante no andamento do texto produzido pelo professor em ambos os contextos, não como um inspetor que propõe buscar erros ou falhas na organização das experiências narradas pelo docente, mas um trabalho de mediação e interação que possa direcionar o pensamento crítico e reflexivo do professor acerca das trajetórias evocadas traduzidas em palavras.

\subsection{Diário biográfico-educativo}

O diário biográfico apresenta para a educação um ganho significativo sobre as representações, sentidos e significados das práticas vivenciadas pelos professores no desenvolvimento formativo e na prática pedagógica. Para Bolívar; Domingo; Fernández (2001, p. 183), esse instrumento pode assumir uma escrita de "cunho descritivo, etnográfico, analítico, evolutivo e reflexivo", ou integrado. De acordo com os autores, o diário como dispositivo de formação permite que os professores desenvolvam um olhar e pensar reflexivo acerca das experiências e vivências, de modo pontual ou permanente, pois ao escrever em seus diários os docentes emitem opiniões, sentidos e interpretações acerca do fenômeno observado e experienciado. 
Como instrumento de pesquisa, o diário biográfico torna-se um recurso significativo na compreensão do clico de vida e desenvolvimento profissional. Nesse caso, por meio das narrativas escritas é observar e analisar as interfaces pontuais ou permanentes sobre as possibilidades, dilemas e desafios que emergem na formação e prática dos professores. Somado a isso, a produção narrativa dos professores permite o desenvolvimento do conhecimento de si e do Outro, como parte da constituição da sua identidade.

Para Zabalza (2004, p. 17), a escrita dos diários no seio do processo educacional, como por exemplo, o subgênero, o diário de aula, "permitem aos professores revisar elementos de seu mundo pessoal que frequentemente permanecem ocultos à sua própria percepção, enquanto está envolvido nas ações cotidianas de trabalho". Desse modo, esse é um instrumento de formação, reflexão e conhecimento de si para o professor, pois os dilemas e possibilidades podem ser evidenciados num processo de revisão e avaliação ao longo do processo formativo e de trabalho. Dessa maneira,

Os diários contribuem de uma maneira notável para o estabelecimento dessa espécie de círculo de melhoria capaz de nos introduzir em uma dinâmica de revisão e enriquecimento de nossa atividade como professores. Esse círculo começa pelo desenvolvimento da consciência, continua pela obtenção de uma informação analítica e vai se sucedendo por meio de outras séries de fases, a previsão das necessidades de mudanças, a experimentação das mudanças e a consolidação de um novo estilo pessoal de atuação. (ZABALZA, 2004, p. 11)

Cabe ressaltar que o diário de aula não corresponde diretamente à organização e ao conteúdo ministrado pelo professor em classe, mas um trabalho de narração entre impressões pessoais, desenvolvimento pedagógico e profissional (ZABALZA, 2004). Assim, a escrita proporciona aos docentes, formadores e pesquisadores olhares e perspectivas referentes à docência, as implicações pessoais, institucionais e profissionais que atravessam e marcam o desenvolvimento profissional dos professores.

O diário pode ser também um instrumento de revisão e avaliação do professor na melhoria do fazer pedagógico no contexto da sala de aula (PORLÁN; MARTíN, 1997). A produção narrativa nesse texto, como os demais citados, favorece a tomada de consciência do docente, no que diz respeito ao 
desenvolvimento profissional e suas referências. De modo similar, essa prática narrativa vem contribuir para o estabelecimento de conexões entre o conhecimento prático e teórico experienciados pelo professor.

\section{5. À GUISA DE CONCLUSÃO}

A reflexão tecida nesse trabalho reforça a importância da narrativa (auto) biográfica para a compreensão da trajetória de vida pessoal e profissional dos professores. Acreditamos que o uso da narrativa no campo da formação docente vem ampliar e fortalecer o debate sobre o papel do professor como sujeito de saberes e detentor de subjetividade, principalmente, frente às incertezas que assolam o país no momento, no âmbito dos cursos de professores e as reformas empreendidas pelo governo nos níveis fundamental e médio da Educação Básica.

Em outro ângulo, entendemos que a narrativa, seja por meio do memorial de formação seja pelo diário educativo, além de fomentar a formação e desenvolvimento do docente, permite o pesquisador analisar essas produções escritas como "instrumentos produtores de subjetividades, relevadas ou ocultadas, pela narração segundo as condições sociais e históricas" (CÂMARA; PASSEGGI, 2013, p. 45). Por conseguinte, muito além da transmissão ou relato de uma informação, as narrativas escritas na formação potencializam a história de vida dos professores e sua existência humana.

\section{REFERÊNCIAS}

BAKHTIN, Mikhail. Estética da criação verbal. São Paulo: Martins Fontes, 2003.

BOLÍVAR; Antonio; DOMINGO; Jesús; FERNÁNDEZ, Manuel. La investigación biográfico-narrativo en educación: enfoque y metodología. Madrid: La Muralla, 2001.

BOSI, Ecléa. Memória e sociedade: lembranças de velhos. 3. ed. São Paulo: Companhia das Letras, 1994.

CÂMARA; Sandra Cristinne Xavier; PASSEGGI, Maria da Conceição. Memorial autobiográfico: uma tradição acadêmica no Brasil. In: PASSEGGI, Maria da Conceição; VICENTINI, Paulo Perin; SOUZA, Elizeu Clementino (Orgs.). Pesquisa (auto)biográfica: narrativas de si e formação. Curitiba: CRV, 2013. p. 29-48. 
CLANDININ, D. Jean; CONNELLY, F. Michael. Pesquisa narrativa: experiência e história em pesquisa qualitativa. Tradução: Grupo de Pesquisa Narrativa e Educação de Professores ILEEI/UFU. Uberlândia: EDUFU, 2015.

FERRAROTTI, Franco. Sobre a autonomia do método biográfico. In: NÓVOA, António; FINGER, Matthias (Org.). O método (auto)biográfico e a formação. Natal, RN: EDUFRN; São Paulo: Paulus, 2010.

FONTOURA; Helena Amaral. Narrativas de um grupo em constante caminhar. Quando contamos nossas histórias de aprendizagem. In: MORAES, Dislane Zerbinatti; LUGLI, Rosário Silvana Genta (Org.). Docência, pesquisa e aprendizagem: (auto)biografias como espaços de formação/investigação. São Paulo: Cultura Acadêmica, 2010. p. 89-109.

GUIMARÃES, Selva. Ser professor no Brasil: história oral de vida. 3. ed. Campinas: Papirus, 1997.

HOLLY, Mary L. Investigando a vida profissional dos professores: diários biográficos. In: NÓVOA, A.(Ed.). Vidas de professores. Porto: Porto Editora, 1992. p. 79-110.

JOSSO, Marie-Christine. Da formação do sujeito... ao sujeito da formação. In: NÓVOA, António; FINGER, Matthias (Org.). 0 método (auto)biográfico e a formação. Natal, RN: EDUFRN; São Paulo: Paulus, 2010.

Experiências de vida e formação. Trad. José Claudino e Júlia Ferreira. São Paulo: Cortez, 2004.

LARROSA, Jorge. Notas sobre a experiência e o saber de experiência. Rev. Bras. Educ, 2002, n.19, pp.20-28.

MORINÃ, Anabel. Investigar con Historias de Vida: metodología biográficonarrativa. Madrid: Narcea, 2017.

NÓVOA, António; FINGER, Matthias (Org.). 0 método (auto)biográfico e a formação. Natal: EDUFRN; São Paulo: Paulus, 2010.

OLIVEIRA, Rosa Maria Moraes Anunciato de. Narrativas: contribuições para a formação de professores, para as práticas pedagógicas e para a pesquisa em Educação. Revista de Educação Pública. Cuiabá, v. 20, n. 43, p. 289-305, maio/ago. 2011.

PASSEGGI, Maria da Conceição. Narrar é humano! Autobiografar é um processo civilizatório. In: PASSEGGI, Maria da Conceição; SILVA, Vivian Batista (Orgs.). Invenções de vida, compreensão de itinerários e alternativas de formação. São Paulo: Cultura Acadêmica, 2010. p. 103-130.

PORLÁN, Rafael Ariza; MARTíN, José Toscano. El diário del professor: um recurso para la investigación en el aula. Sevilla: Díada Editora, 1997. 
RAMOS, Michael Daian P.; OLIVEIRA, Rita de Cássia M.; SANTOS, Maria Rita. Estado da arte da pesquisa (auto) biográfica: uma análise do portal de periódicos Capes. Revista Brasileira de Pesquisa (Auto) Biográfica, Salvador, v. 02, nํ․ 05, p. 449-469, maio/ago. 2017.

SILVA, Tomaz Tadeu da. Documentos de identidade: uma introdução às teorias do currículo. Belo Horizonte: Autêntica, 2015.

SOARES; Sebastião Silva; FONSECA, Eliana Gonçalves da Silva. A pesquisa e escrita (auto)biográfica com professores: entre princípios conceituais e dimensões práticas. In: BIEGING, Patrícia; BUSARELLO, Raul Inácio. Cultura, história de vida e memória: lugares de enunciação. São Paulo: Pimenta Cultural, 2018. p. 99-120.

SOUZA, Elizeu Clementino de. A formação como processo de conhecimento: História de vida e abordagem (auto)biográfica. In: BRAGANÇA, Inês Ferreira de Souza et al. (Orgs.). Vozes da Educação: memórias, histórias e formação de professores. Petrópolis: DP et Alii; Rio de Janeiro: Faperj. 2008. p. 85-102.

TARDIF, Maurice. Saberes docentes e formação profissional. Petrópolis: Vozes, 2014.

ZABALZA, Miguel. Diários de aula: um instrumento de pesquisa e desenvolvimento profissional. Porto Alegre: Artmed, 2004. 